\title{
Evaluation of different rice genotypes for resistant against rice root-knot nematode, Meloidogyne graminicola
}

\author{
Vinod Kumar*, Anil Kumar and S.S. Mann \\ Department of Nematology, C.C.S. Haryana Agricultural University, Hisar (Haryana) India \\ (Email: vinodnagal09@gmail.com)
}

\begin{abstract}
Screening of different rice genotypes were tested for their resistant reaction against rice root-knot nematode, Meloidogyne graminicola. In the present studies, 79 rice genotypes/lines (44 genotypes from OG series and 35 genotypes from AR series including Pusa 1121 and TN-1 as susceptible checks) were evaluated for resistant reaction against M. graminicola was carried out under screen house, Department of Nematology, CCS Haryana Agricultural University, Hisar, Haryana during Kharif, 2019-20. Seeds of each genotype were sown in the earthen pots ( $1 \mathrm{~kg}$ soil capacity) containing steam sterilized sandy loam soil. One week old seedlings of rice genotypes were inoculated with freshly hatched second stage juveniles of M. graminicola @ $2000 \mathrm{~J}_{2} /$ pot. Forty five days after inoculation, observations were recorded such as number of eggs and second stage juveniles. The result reveals that the genotypes showed great variation in reaction to $M$. graminicola from resistant to highly susceptible reaction. Out of 44 genotypes from OG series, 34 showed resistant reaction. However, two genotypes (OG-4 and OG-37) were found moderately resistant and remaining was categorized as susceptible reaction. Similarly, out of 35 genotypes from AR series, two genotypes (AR-08, AR-31) showed resistant reaction against M. graminicola. Four genotypes (AR-06, AR-20, AR-21 and AR-32) showed moderately resistant reaction and rests of the genotypes were categorized as susceptible reaction against $M$. graminicola. Most of the genotypes were found resistant/moderately resistant to M. graminicola which can be used for future breeding programmes to develop resistant reaction in these genotypes.
\end{abstract}

Key Words : Meloidogyne graminicola, Rice, Resistant, Screening, Genotypes

View Point Article : Kumar, Vinod, Kumar, Anil and Mann, S.S. (2020). Evaluation of different rice genotypes for resistant against rice rootknot nematode, Meloidogyne graminicola. Internat. J. agric. Sci., 16 (2) : 249-253, DOI:10.15740/HAS/IJAS/16.2/249-253. Copyright@ 2020: Hind Agri-Horticultural Society.

Article History : Received : 26.04.2020; Revised : 19.05.2020; Accepted : 23.05.2020

\footnotetext{
* Author for correspondence :
} 